\title{
O ensino da língua brasileira de sinais na modalidade a distância e a formação docente
}

\section{The teaching of brazilian sign language at a distance and teacher training}

\author{
DOI: $10.46814 /$ lajdv3n4-050
}

Recebimento dos originais: 01/05/2021

Aceitação para publicação: 31/06/2021

Edilene Mizael De Carvalho Perboni

Doutora em Educação pela Universidade São Francisco Campus Itatiba/SP. E-mail:didisre@yahoo.com.br

Adriana De Cássia Santana Silva

Graduadas em Pedagogia pela Universidade do Estado de Minas Gerais Poços de Caldas/MG

E-mail: drykacassia@hotmail.com

Ana Carolina Sandry Francisco Dos Reis

Graduadas em Pedagogia pela Universidade do Estado de Minas Gerais Poços de Caldas/MG E-mail: anacarolinasandry@yahoo.com.br

\section{Luana Karina Siqueira}

Graduadas em Pedagogia pela Universidade do Estado de Minas Gerais Poços de Caldas/MG E-mail: luana.siqueira26@yahoo.com.br

\section{Solange Aparecida Sebastião}

Graduadas em Pedagogia pela Universidade do Estado de Minas Gerais Poços de Caldas/MG E-mail: solsebastiao6@gmail.com

\section{RESUMO}

Este estudo investiga o ensino da língua brasileira de sinais na modalidade a distância em um curso de formação de professores. Tem como objetivo compreender as implicações conceituais, metodológicas e práticas na formação inicial de pedagogos. Divide-se em três seções pelas quais foi possível desenvolver objetivos específicos e educação de surdos nos contextos históricos mundial, de Brasil e Minas Gerais; conhecer, na visão dos gestores, quais as implicações pedagógicas e institucionais interferem na implantação desse processo, a partir do que foi possível destacar quais limites se apresentam para o processo de ensino e aprendizagem da língua brasileira de sinais a distância na formação docente. Os procedimentos metodológicos utilizados se basearam em fundamentos da pesquisa qualitativa; os estudos teóricos se fundamentaram em autores que debatem a educação de surdos, o ensino da língua de sinais e a educação a distância, cujos referenciais teóricos e legais foram coletados em repositórios institucionais de teses e pesquisas, sites institucionais da área da educação e de legislações referentes aos temas investigados, bem como no Scientific Eletronic Library Online (SciELO) e em periódicos científicos educacionais atuais.

Palavras-chave: Formação docente, Ensino da língua brasileira de sinais, Educação a distância, Educação de surdos. 


\section{ABSTRACT}

This study investigates the teaching of Brazilian Sign Language at a distance in a teacher education course. It aims to understand the conceptual, methodological and practical implications in the initial training of educators. It is divided into three sections through which it was possible to develop specific objectives and deaf education in the historical contexts of the world, Brazil and Minas Gerais; to know, in the view of managers, what pedagogical and institutional implications interfere with the implementation of this process, from which it was possible to highlight what limits are presented for the process of teaching and learning Brazilian sign language at a distance in teacher training. The methodological procedures used were based on qualitative research foundations; the theoretical studies were based on authors who discuss deaf education, sign language teaching and distance education, whose theoretical and legal references were collected in institutional repositories of theses and research, institutional websites in the field of education and legislation on the topics investigated, as well as in the Scientific Electronic Library Online (SciELO) and in current educational scientific journals.

Keywords: Teacher training, Teaching Brazilian Sign Language, Distance education, Deaf education.

\section{INTRODUÇÃO}

Nasce na Universidade do Estado de Minas Gerais (UEMG), Unidade Poços de Caldas, no decorrer do segundo semestre do ano letivo de 2018 o interesse pelo tema "O Ensino da Língua Brasileira de Sinais na modalidade a distância e a formação docente" que se deveu ao fato de a disciplina Introdução à Língua Brasileira de Sinais (Libras) fazer parte dos componentes curriculares que são ofertados aos alunos do Curso de Pedagogia.

Para que fosse possível atingir o objetivo geral do estudo, buscou-se, com base nos fundamentos da pesquisa qualitativa, organizar o percurso metodológico de investigação iniciando pela pesquisa em referenciais teóricos que possibilitassem um estudo analítico relacionado ao tema.

Sobre a abordagem qualitativa de pesquisa, Vilelas (2009) a considera como forma de estudar de modo privilegiado os problemas; de aliar sua natureza científica e artística para seja possível compreender e dar sentido às experiências da sociedade e como as pessoas as interpretam.

No que se refere às fontes de pesquisa, Lankshear e Knobel (2008) afirmam que por serem produzidas o mais próximo possível das ações, passam a se caracterizar como detonadoras do pensamento e da sequência de pensamentos específicos.

Assim ficaram também definidos os objetivos específicos: conceituar Libras, compreender as peculiaridades culturais, linguísticas e de necessidades educacionais especiais dos surdos; reconhecer o processo histórico sobre o reconhecimento da pessoa surda como sujeito de direito à educação e ao convívio escolar; e compreender, no contexto histórico, como foram e como são organizadas atualmente as tecnologias da informação e comunicação (TICs) e a metodologia do ensino de Libras em EAD.

Também se evidenciou a necessidade de analisar por que os cursos de licenciatura estão 
optando pela oferta da disciplina Libras em EAD, considerando-se os possíveis impactos pedagógicos na formação dos pedagogos formados em cursos de graduação que oferecem a disciplina de Libras nessa modalidade; e como e quando surgiu no Brasil e em Minas Gerais a concepção do ensino Libras em EaD. A partir dessas considerações, no sentido de desenvolver o tema, procedeuse ao desenvolvimento do planejamento e processo metodológico de estudos teóricos e de pesquisa já definidos, que nessa fase consistiu na coleta de dados em repositórios institucionais de teses e pesquisas, sites institucionais da área da educação e de legislações referentes aos temas investigados, bem como no Scientific Eletronic Library Online (SciELO) e em periódicos científicos educacionais atuais.

\section{O ENSINO DA LÍNGUA BRASILEIRA DE SINAIS NA FORMAÇÃO DOCENTE}

Ensinar a língua brasileira de sinais (Libras) é um desafio, tanto na educação de pessoas surdas quanto na formação dos professores que irão atuar nessa educação. Nesse sentido, Muttão e Lodi (2018), em estudos realizados sobre a importância da formação dos professores para atuarem na educação básica em um contexto de educação inclusiva para os surdos, concluíram que "[...] as especificidades da educação de surdos não têm sido contempladas na formação inicial, ao restringir a formação do professor à disciplina Libras “(MUTTÃO)

Com o objetivo de possibilitar a compreensão inicial sobre a questão tema deste estudo, o ensino de Libras na modalidade a distância na formação de professores, foi desenvolvida coleta de dados em campo, onde buscamos registrar as representações de alunos do Curso de Pedagogia da UEMG, Unidade Poços de Caldas.

Na disciplina de Libras na modalidade EAD, são apresentados dados, conhecimentos, noções, referenciais sobre a cultura da língua de sinais, com o objetivo de fazer com que os futuros pedagogos, ao terem contato com a Libras, adquiram conhecimentos que os permita estarem melhor preparados para lidar com as demandas dos alunos surdos que venham a encontrar durante sua trajetória docente.

No entanto, essa falta de conteúdo que é apresentada na disciplina de Libras na modalidade à distância, pode vir a ser um incentivo e aumentar o interesse do aluno pela procura por conteúdos com aulas presenciais, possibilitando uma continuidade em seus estudos.

Modalidade à distância carrega desafios, essencialmente em relação à compreensão do aprendiz, no direcionamento dos conceitos básicos do uso da língua e também na reflexão da construção do conhecimento adquirido.

Vale salientar que a Libras é uma língua que necessita do gesto, do visual, do corpo, e por isso somente apresentar aulas com conteúdo de leitura, figuras, textos, acaba fazendo com que o aluno que 
cursa essa modalidade de ensino não aprenda o necessário, não tendo o proveito suficiente que o habilite para se comunicar com uma pessoa surda.

Além do mais é sabido que muitos dos sinais são desenvolvidos através das necessidades sociais e pela interação entre indivíduos e determinados contextos, e conforme afirmam Bernardino e Passos (2011, p.1283): “Outro aspecto importante a ser considerado é que todo aprendizado de língua pressupõe o aprendizado também de temas como a cultura e os costumes adotados pelos seus "falantes", ou pelos seus usuários".

Pela observação dos aspectos apresentados e pela coleta de dados em campo não satisfatória dos alunos do Curso de Pedagogia Unidade Poços de Caldas quanto a oferta da disciplina na modalidade a distância e conforme apontam Bernardino e Passos (2011), entende-se a importância de problematizar a oferta da disciplina de Libras na modalidade a distância, visto que para um aprendizado de qualidade é necessário que haja interação entre os envolvidos, considerando sua cultura e costumes.

\section{EDUCAÇÃO NA MODALIDADE A DISTÂNCIA E A EDUCAÇÃO DE SURDOS}

A educação a distância (EAD) é uma modalidade de educação pela qual, ao serem utilizados recursos tecnológicos de informação e comunicação, oportuniza-se os processos de ensino e aprendizagem em uma relação dialética diferenciada para alunos e professores. Assim, na modalidade de educação a distância, discentes e docentes estão separados por tempo e espaço diversos, porém podem estar conectados em ambientes virtuais de comunicação.

Nesse sentido, pelo documento Referenciais de Qualidade para Educação Superior a Distância, do Ministério da Educação, pensar a prática dessa modalidade de educação nos leva a refletir,

[...] a respeito da necessidade de ressignificações de alguns paradigmas que norteiam nossas compreensões relativas à educação, escola, currículo, estudante, professor, avaliação, gestão escolar, dentre outros (BRASIL, 2007, p. 3).

De acordo com Nunes (2009), o marco inicial da educação a distância, teve a contribuição do professor Caleb Philips, que em 1728, proporcionou um ensino e tutoria por correspondência. Atualmente, a oferta de cursos na modalidade a distância é regida pelo Decreto $\mathrm{N}^{\circ} 9.057$, de 25 de maio de 2017 (BRASIL, 2017), que ao regulamentar o Art. 80 da Lei de Diretrizes e Bases da Educação Nacional (BRASIL, 1996), estabelece:

Art. $1^{\circ}$ Para os fins deste Decreto, considera-se educação a distância a modalidade educacional na qual a mediação didático-pedagógica nos processos de ensino e aprendizagem ocorra com a utilização de meios e tecnologias de informação e comunicação, com pessoal qualificado, com políticas de acesso, com acompanhamento e avaliação 
compatíveis, entre outros, e desenvolva atividades educativas por estudantes e profissionais da educação que estejam em lugares e tempos diversos.

A EAD no Brasil passou por períodos de grandes avanços e também retrocessos. Tal fato se deveu à falta de políticas públicas para a modalidade. O Brasil por algum tempo esteve entre os principais no mundo ao se tratar do desenvolvimento da educação a distância, em particular até os anos 70; após essa época outros países ganharam destaque e só por volta dos anos 90 o Brasil ganha novamente visibilidade na modalidade. Vale salientar que a ascensão da educação a distância no Brasil foi marcada pela ascensão também dos meios de comunicação, passando pela fase do uso da correspondência escrita, do rádio, da televisão, até chegar aos dias de hoje com a forte influência da tecnologia (PEREIRA; MORAES; TERUYA, 2017).

No ano de 1996 a educação à distância no Brasil se solidifica, tornando seu espaço oficialmente ancorado pela Lei de Diretrizes e Bases da Educação Nacional nº 9.394, 20 de dezembro de 1996, mesmo que já tenha sido regulamentada pelo Decreto № 5622, de 19 de dezembro de 2005 (BRASIL, 2005). A partir de então surgiram várias redes de ensino que passaram a ofertar cursos de graduação, pós- graduação e extensão na modalidade à distância.

No início do século XXI, a educação na modalidade a distância passou por grandes modificações e ganhou respaldo governamental com a publicação de várias portarias e decretos, pelos quais foi possível solidificar e fortalecer seu espaço. Um desses documentos que teve grande destaque foi a Portaria do Ministério da Educação N².253, de 18 de outubro de 2001, que se referia à inserção de disciplinas à distância em cursos presenciais nas instituições de ensino superior federais. Essa Portaria foi depois reformulada pala Portaria $N^{\circ}$ 4.059, de 10 de dezembro de 2004 (BRASIL, 2004), que passou a regulamentar tal ação não só para as instituições federais, mas também para todas as demais. Em seu Art. $1^{\circ}$ dispõe: “[...] As instituições de ensino superior poderão introduzir, na organização pedagógica e curricular de seus cursos superiores reconhecidos, a oferta de disciplinas integrantes do currículo que utilizem modalidade semi-presencial [...]”(BRASIL, 2004).

A Portaria No 4.059/2004 determina também que 20\% da carga horária do curso presencial poderá ser ofertada na modalidade à distância, onde alunos e professores estarão em espaços distintos e não necessariamente conectados ao mesmo tempo. Determina ainda que os conteúdos de aprendizado considerados essências serão ofertados de modo presencial, enquanto as disciplinas complementares serão ofertadas na modalidade a distância. Vale salientar que a instituição que opte por oferecer disciplina nessa carga horária, não terá a obrigatoriedade de ser credenciada como modalidade EAD. A inclusão da disciplina deverá constar no projeto pedagógico do curso e as avaliações terão que ser aplicadas de forma presencial, conforme citam Azevedo, da Luz e Fontes (2018, p. 11): 
Também em 2016, foi publicada a Portaria no 1.134, de 10 de outubro, que revoga a Portaria $\mathrm{N}^{\mathrm{o}} 4.059 / 2004$, atualizando a terminologia de disciplina "semipresencial" para disciplinas na modalidade "a distância", que poderão ser ofertadas total ou parcialmente nessa modalidade, estando as avaliações sujeitas a encontros presenciais e com previsão de tutoria por profissionais qualificados.

Com a inserção de disciplinas ofertadas nessa modalidade, fica evidente o quanto as tecnologias da informação e comunicação (TICs) estão cada vez mais presentes em nosso cotidiano; e a partir de tanta procura por cursos nessa modalidade, podemos perceber maior responsabilidade de profissionais qualificados para atuarem em tal modalidade.

A expansão da Educação a Distância pelo mundo, segundo Pelli e Vieira 2018), sua evolução teve início no século XVIII, sendo que inicialmente se utilizava do correio para enviar instruções e informações, bem como transmitir aulas de diversas áreas do conhecimento; as lições eram enviadas e as respostas eram recebidas dos alunos. Essa modalidade de educação passou a ofertar uma alternativa para suprir a educação presencial quando os indivíduos não tinham condições de cursar o ensino regular, visto que, muitos residiam em áreas isoladas. Porém, nem sempre essa nova metodologia de ensino e aprendizagem teve aceitação irrestrita e imediata.

Podemos compreender que a educação a distância passou por retrocessos, visto que não era fundamentada adequadamente com políticas públicas; e mesmo a sua institucionalização ainda passando por grandes dificuldades houve quem ousasse para que aos poucos a educação a distância se solidificasse e ganhasse seu espaço, progredindo então no campo educacional.

\subsection{A EDUCAÇÃO DE SURDOS: O SUJEITO HISTÓRICO E O CONTEXTO EDUCATIVO}

Para Almeida (2015, p. 10), pensar a educação de surdos nos leva a buscar compreender a pessoa com surdez como um sujeito histórico, de aspectos cultural e linguístico diferenciados, assim como a entender que é nesse diferenciamento que se encontram os elementos de seu empoderamento, que lhe permitirá tomar posse de seu espaço de conhecimento no espaço educativo, posse essa que o constituirá realmente como sujeito.

Escritos sobre a história da educação dos surdos citam a antiguidade como período no qual os primeiros relatos dão conta de que pessoas com essa condição já faziam parte de questões tratadas pela sociedade, onde os surdos eram vistos como criaturas enviadas pelos "deuses", com os quais se comunicavam, ou como pessoas “enfeitiçadas”, por eles castigadas (STROBEL, 2009).

A educação de crianças portadoras de surdez era planejada por seus familiares, que contratavam tutores de forma individualizada, realizada por médicos ou religiosos com a finalidade de ensinar os deficientes auditivos a se comunicarem de forma oral ou escrita. Os métodos utilizados no aprendizado eram muito congêneres, ou seja, os tutores aplicavam a fala, a escrita, o alfabeto 
manual e os sinais. De acordo com Pereira et al. (2011, p.7). "Nessa época os professores ocultavam os métodos utilizados, pois sentiam a necessidade de manter segredo. Devido a esse fato as informações de como as crianças surdas eram educadas são insuficientes".

A primeira iniciativa de fundação de uma escola para educar pessoas surdas que se tem conhecimento, data de 1791, dois séculos após as primeiras tentativas de instituição de uma educação com esse objetivo. A iniciativa foi concebida pelo religioso francês Michel de L'Epée (1712-1789), que desenvolveu um método gestualístico que pode ser entendido como a primeira prática de educação para surdos, considerando que os surdos já tinham uma linguagem mímica (MOURA, 2000 apud MIRANDA, 2014).

Com esse método, L’Epée fundou em 1760, em Paris, a primeira escola para surdos do mundo, fazendo com que a língua de sinais passasse a ser reconhecida, divulgada e valorizada, privilegiando a Língua de Sinais Francesa (LSF) que havia aprendido com os surdos nas ruas de Paris. Com essa iniciativa L'Epée visava demonstrar que as pessoas surdas, mesmo sem poder falar, eram seres humanos como qualquer outra pessoa. A partir de seus resultados, L'Epée ficou conhecido como “O pai dos surdos" por haver desenvolvido uma forma diferenciada de educar os surdos. Criou em 1778 o Instituto Nacional dos Surdos e seus métodos foram desenvolvidos em outros países (PEREIRA et al., 2011).

Na história da educação de surdos no Brasil, Dom Pedro II teve uma importante participação, ao contratar o professor francês Hernest Huet, também surdo, que foi o criador, em 1857, da primeira escola para surdos no Brasil, o Instituto Nacional de Educação de Surdos (INES), que inicialmente ensinava os alunos surdos pela Língua de Sinais Francesa (LSF). Posteriormente, o professor Huet criou a Língua Brasileira de Sinais (Libras), que possibilitou uma melhor comunicação entre os surdos e os não surdos. Porém, desde a sua fundação o Instituto não era bem visto pela população, que não reconhecia nem confiava no trabalho do professor Huet. E pelo fato de não ser brasileiro e também surdo, muitos surdos não frequentavam o Instituto. Contudo, ao longo do tempo acabou por ser aceito pela sociedade, e após cinco anos de trabalho com os surdos no Brasil, Hernest Huet saiu do país, deixando a continuidade do seu trabalho em mãos de educadores brasileiros (OLIZAROSKI, 2013).

Algumas pesquisas recentes apresentam que a propositura mais adequada da modalidade bilíngue se faz pertinente ao ensino de crianças portadoras de surdez. Segundo (PERLIN; STROBEL, 2008, p.15), surdas, tendo em vista que considera a língua de sinais como primeira língua e a partir daí se 
passam para o ensino da segunda língua que é o português que pode ser na modalidade escrita ou oral (PERLIN; STROBEL, 2008, p. 15).

Nesse sistema, uma vez que se acata como sendo a primeira língua das pessoas surdas a língua de sinais, posteriormente é ensinada a língua portuguesa, tanto na forma oral como escrita, que será, então, tida como a segunda língua do surdo. Perlin e Strobel (2008, p.16) citam ainda que: “[...] na ideologia de bilinguismo as crianças surdas precisam ser postas em contato primeiro com pessoas fluentes na língua de sinais, sejam seus pais, professores ou outros". Ou seja, segundo os princípios de bilinguismo, crianças portadoras de surdez necessitam ter o contato primeiramente com pessoas que se comuniquem constantemente na linguagem de sinais e somente após esse contato, partir para o aprendizado de uma segunda língua.

Em relação à educação de surdos no estado de Minas Gerais, em 10 de Janeiro de 1991, é criada a Lei Estadual No 10379 (MINAS GERAIS, 1991), que passa a reconhecer oficialmente como meio de comunicação objetiva e de uso corrente, a linguagem gestual codificada na Língua Brasileira de Sinais (Libras).

O então governador, Sr. Newton Cardoso, determinou que o Estado deveria inserir nas repartições públicas que são voltadas para o atendimento externo, profissionais interpretes da língua de sinais. Também, a Libras foi incluída no currículo da rede pública estadual de ensino, estendendose aos cursos de magistério, formação superior nas áreas das ciências humanas, médicas e educacionais e as instituições que se voltam ao aluno portador de deficiência auditiva.

Em 1999, é sancionada a Lei Municipal de $\mathrm{N}^{\mathrm{o}} 7793$, de 3 de setembro, composta por três artigos, pela qual o povo do município de Belo Horizonte, juntamente com o Prefeito da época, Sr. Célio de Castro, instituíram,

[...] o Dia Municipal dos Surdos, a ser comemorado, anualmente, no dia 26 de setembro. Art. $2^{\circ}$ - O Executivo, por intermédio de seu órgão competente, promoverá atividades que contribuam para uma reflexão sobre a condição de vida do surdo, possibilitando-lhe maior inserção social e política. Parágrafo único - As atividades referidas no caput deste artigo deverão subsidiar a elaboração de políticas do governo que favoreçam o surdo. Art. $3^{\circ}$ Esta Lei entra em vigor na data de sua publicação (BELO HORIZONTE, 1999).

Destaca-se no ano de 2002, conforme a Lei № 14367, de 19 de Julho de 2002, que determina, em instituições de ensino superior da rede estadual de ensino, condições para atendimento a pessoas com necessidades especiais que buscam ingressar nos cursos oferecidos por essas instituições; a referida Lei, em seu Art. $2^{\circ}$ inciso V, considera como uma das condições de atendimento "[...] presença de intérprete de língua de sinais" (MINAS GERAIS, 2002). Após a implantação dessa Lei, os surdos puderam, então, solicitar o interprete em salas de aula, teatros e em outros locais que seja necessário 
alguém para mediar a comunicação.

Já o ano de 2006, tem como marco inicial o Dia Estadual do Surdo, instituído no Estado conforme Lei $\mathrm{N}^{\mathrm{o}}$ 16500, de 21 de dezembro de 2006, que assim determina: "Art. $1^{\text {o }}$ Fica instituído o Dia Estadual dos Surdos, a ser comemorado, anualmente, no dia 26 de setembro. Art. $2^{\circ}$ Esta Lei entra em vigor na data de sua publicação. Palácio da Liberdade, em Belo Horizonte, aos 21 de dezembro de 2006.” (MINAS GERAIS, 2006).

\section{O ENSINO DA LÍNGUA BRASILEIRA DE SINAIS NA MODALIDADE A DISTÂNCIA: UNIVERSIDADE DO ESTADO DE MINAS GERAIS - POÇOS DE CALDAS}

Em entrevistas com os gestores do Curso de Pedagogia, o objetivo foi obter informações quanto à opinião dos gestores da unidade perante as mudanças ocorridas na forma de oferecimento da disciplina Introdução à Língua Brasileira de Sinais, visto que o curso é presencial. O formulário de entrevista para coleta das informações e opiniões dos entrevistados foi elaborado e aplicado no mês de dezembro de 2019.

Observou-se que a disseminação da educação na modalidade a distância está em expansão, porém a disciplina de Libras ministrada em EaD pode ser um fator preocupante, por se tratar de conteúdo relacionado a gesto e expressão; ou por falta de adequação de materiais didáticos.

Considera-se que a incompreensão adquirida sobre a linguagem de sinais pode deixar lacunas na formação docente e assim dificultar a aprendizagem da Libras por ausência de materiais didáticos de qualidade. Neste sentido, as plataformas de acesso aos recursos e conteúdos têm que oferecer um alinhamento técnico e pedagógico acessíveis. Ou seja, todos os responsáveis têm que ter conhecimento sobre a linguagem das novas tecnologias e serem habilitados em ensinar, para garantir que os discentes tenham uma formação de qualidade, com apoio para organização do processo de aprendizagem, de forma a suprir todas as suas necessidades durante o curso.

No entender de Santos et al. (2015), apesar dos avanços atuais na área das tecnologias, ainda se percebe as limitações do processo de ensino e aprendizagem, visto que na educação a distância ainda são inúmeras as dificuldades que se apresentam, o que, na questão da formação e atuação docentes, pode comprometer significativamente a qualidade do ensino. Para os autores,

\footnotetext{
Por ser uma modalidade de ensino relativamente nova, são inúmeros os desafios para os profissionais, que não estão apropriadamente preparados para assumir essas novas funções pedagógicas, e também para os alunos, que não desenvolveram o hábito de participar ativa e autonomamente do processo de apropriação do conhecimento ofertado pela educação a distância (SANTOS et al., 2015, p. 205).
}

Tal argumento nos conduz a pensar no contexto da educação a distância na formação de professores, onde é preciso incorporar novos hábitos no processo de aprendizagem. Para Tarcia e 
Cabral (2012, p. 150), é preciso que o futuro educador “[...] se aproprie do universo de conhecimentos e de práticas envolvidos no contexto da educação a distância e, a partir daí, assume o papel exigido". Entende-se, dessa forma, que o aluno deverá vivenciar essa nova dimensão tecnológica, na qual se apropriará de instrumentos conceituais e formativos para sua futura prática docente.

Em relação à prática do ensino de Libras a distância, ter um profissional professor presencial que conheça a cultura surda e possa mediar esses saberes, pode proporcionar aos futuros pedagogos atender melhor às demandas diante da inclusão dos alunos surdos nas salas de aula.

Lebedeff et al. (2011, p. 3) afirmam que:

Por ser uma língua viso-espacial, a Libras apresenta peculiaridades específicas distintas das línguas orais; como cenário da Libras temos a cultura surda e seus artefatos, esta muitas vezes desconhecida pela maior parte dos acadêmicos, aos quais chamaremos de Zero Libras - ZL, ou seja, sujeitos que não possuem saberes sobre o sujeito surdo e a sua cultura, sobre a língua de sinais e a Libras. Percebe-se, portanto, o desafio de introduzir os saberes sobre a surdez na modalidade a distância em comunidades que geralmente desconhecem a surdez como diferença linguística e a Língua Brasileira de Sinais como língua de uma comunidade linguística minoritária (LEBEDEFF et al., 2011, p. 3).

Fica claro que as instituições formadoras de profissionais da área de educação precisam estabelecer medidas adequadas para o processo de formação para o ensino e aprendizagem, buscando a mediação de profissionais que conheçam a cultura surda, seus artefatos e metodologias de ensino. Muitas vezes, como disciplinas ofertadas na modalidade distância, tais conhecimentos nem sempre podem ser alcançados, deixando assim lacunas na formação dos docentes. Nascimento e Sofiato (2016) alertam que o tempo de um único semestre pode ser insuficiente para o desenvolvimento da aprendizagem de uma língua de sinais, pois, posteriormente, a qualidade dessa aprendizagem irá determinar a qualidade da prática pedagógica. Importante destacar que o Curso de Pedagogia da Universidade campo dessa pesquisa é um curso presencial, e oferta a disciplina Introdução à língua brasileira de sinais na modalidade a distância.

O Decreto $\mathrm{N}^{\circ} 5.626$ (BRASIL, 2005, n. p.) determina que:

CAPÍTULO II DA INCLUSÃO DA LIBRAS COMO DISCIPLINA CURRICULAR Art. $3^{\circ}$ A LIBRAS deve ser inserida como disciplina curricular obrigatória nos cursos de formação de professores para o exercício do magistério, em nível médio e superior, e nos cursos de Fonoaudiologia, de instituições de ensino, públicas e privadas, do sistema federal de ensino e dos sistemas de ensino dos Estados, do Distrito Federal e dos Municípios.

$\S 1$ o Todos os cursos de licenciatura, nas diferentes áreas do conhecimento, o curso normal de nível médio, o curso normal superior, o curso de Pedagogia e o curso de Educação Especial são considerados cursos de formação de professores e profissionais da educação para o exercício do magistério. § 2o A LIBRAS constituir-se-á em disciplina curricular optativa 
nos demais cursos de educação superior e na educação profissional, a partir de um ano da publicação deste Decreto.

Destaca-se aqui uma problemática no cumprimento do Decreto $\mathrm{N}^{\circ} 5.626$ (BRASIL, 2005), que ao determinar como componente curricular para a formação de educadores o ensino da Libras, não propõe objetivos formativos como, quais os conteúdos, metodologia, carga horário, mas apenas a oferta do que a lei determina, e assim estabelece a precariedade formativa dos profissionais. Cabe, pois, à instituição de ensino proporcionar melhores condições para o desenvolvimento de habilidades e competências formativas, instruindo os futuros profissionais a buscarem mais eficiência na prática educacional para mais acessibilidade e comunicação inclusiva.

Um dos temas recorrentes quando se discute a educação a distância é o papel a ser assumido por um professor, mediador, ou como é denominado nesse contexto, tutor. Tarcia e Cabral (2012) argumentam que nesse espaço, a relação professor-aluno fica transformada. E que devemos ter como perspectiva que em uma modalidade de educação aberta e flexível são estabelecidas novas relações no processo de ensino e aprendizagem, que ocorre de forma dinâmica, mas também compartilhado.

Os procedimentos didáticos para o ensino da língua brasileira de sinais devem contemplar um conjunto de estratégias e ferramentas inovadoras e diferenciadas, as quais podem instrumentalizar os alunos para aquisição de habilidades e o desenvolvimento da criatividade, da interação formativa. Contudo, é necessário o uso de recursos metodológicos, tecnológicos e matérias, que possibilitem ao aluno relacionar teoria e prática e compreender sua utilização.

A atividade presencial no ensino da língua de sinais, uma vez inovada pedagogicamente, pode propiciar ao futuro professor que atue de forma a assegurar ao aluno surdo, direitos reivindicados historicamente, contemplando aspectos linguísticos e de acessibilidade, nos diversos contextos, educacional, profissional, social e cultural. Para tal, é preciso que o professor domine conceitos e práticas sobre as peculiaridades gestuais e visuais da comunicação dos surdos.

Considera-se que, sendo o ensino de Libras ofertado na modalidade presencial, pode se constituir em um ensino mais proficiente para a aprendizagem e formação dos alunos. A educação a distância é uma modalidade de ensino de extrema relevância para o acesso e universalização da educação. Entretanto, ainda necessita de aprimoramentos para que os alunos possam aprender a língua brasileira de sinais de forma eficaz, podendo, assim, atuar em salas de aula no atendimento do direito à educação e inclusão social das pessoas surdas.

\section{CONSIDERAÇÕES FINAIS}

Iniciam-se as considerações com a retomada do problema de pesquisa: quais são as implicações conceituais, metodológicas e práticas para a formação inicial de pedagogos que cursam 
a disciplina de Libras na modalidade de educação a distância (EaD)?; e o objetivo geral do estudo: compreender as implicações conceituais, metodológicas e práticas na formação inicial de pedagogos que cursam a disciplina de Libras na modalidade de educação a distância (EaD).

Os objetivos específicos que nortearam a pesquisa foram conceituar Libras, compreender as peculiaridades culturais, linguísticas e de necessidades educacionais especiais dos surdos; identificar o processo histórico de reconhecimento da pessoa surda como sujeito de direito à educação e ao convívio escolar, assim como compreender como ocorreu a evolução histórica e como são organizadas atualmente as tecnologias da informação e comunicação (TICs) e a metodologia do ensino de Libras em EaD.

O primeiro capitulo teve como objetivo possibilitar a compreensão dos impactos pedagógicos e práticos na formação dos pedagogos em cursos de licenciatura que oferecem a disciplina da Libras em EaD. Através do referencial teórico, Bernardino e Passos (2011) evidenciaram que lidar com a cultura do surdo, é imprescindível para o entendimento de que a pessoa surda apresenta uma identidade própria, sendo, por isso, necessário assimilar essa cultura diferenciada; e no contexto educacional ter compreensão das peculiaridades que são enfrentadas por esse público específico, formado pelos alunos surdos.

A disciplina de Libras na modalidade EaD, deve apresentar também como conteúdo curricular dados, conhecimentos, noções, referenciais sobre a cultura da língua surda, com o objetivo de fazer com que os futuros pedagogos, ao terem contato com a Libras, adquiram conhecimentos que os permita estarem melhor preparados para lidar com as demandas dos alunos surdos que venham a encontrar durante sua trajetória docente.

No capítulo 2, sobre a educação na modalidade a distância e a educação dos surdos, possibilitou pontuar tempos evolutivos e históricos, como quando surgiu no Brasil e em Minas Gerais a concepção do ensino de Libras em EaD; entender por que os cursos de licenciatura estão optando pela oferta da disciplina nessa modalidade e conceituar Libras buscando compreender suas peculiaridades culturais, linguísticas e de necessidades educacionais especiais dos surdos, iniciando por abordar o surgimento da educação na modalidade a distância.

Nota-se que esta é uma modalidade de educação pela qual, ao serem utilizados recursos tecnológicos de informação e comunicação, oportuniza-se os processos de ensino e aprendizagem em uma relação dialética diferenciada para alunos e professores. Assim, na modalidade de educação a distância os discentes e docentes estão separados por tempo e espaço diversos, porém podem estar conectados em ambientes virtuais de comunicação.

Outro grande destaque abordado na pesquisa foi o estudo sobre o início do século XXI, quando a educação na modalidade a distância passou por grandes modificações e ganhou respaldo 
das instâncias governamentais com a publicação de várias portarias e decretos, pelos quais foi possível solidificar e fortalecer sua introdução nos espaços educacionais. Um dos documentos legais que teve grande destaque foi a Portaria do Ministério da Educação № 2.253, de 18 de outubro de 2001, que se referia à inserção de disciplinas à distância em cursos presenciais nas instituições de ensino superior federais. Essa Portaria foi depois reformulada pala Portaria $\mathrm{N}^{\mathrm{o}} 4.059$, de 10 de dezembro de 2004, que passou a regulamentar tal ação não só para as instituições federais, mas também para todas as demais instituições de ensino superior.

O segundo capítulo trouxe também apontamentos sobre a origem e evolução da educação de surdos, abrangendo diversos contextos históricos e evolutivos, como da Língua de Sinais no mundo e da Língua Brasileira de Sinais (Libras) no Brasil e também em Minas Gerais, do século XVI até a atualidade.

A primeira iniciativa de se fundar uma escola para educar pessoas surdas que se tem conhecimento data de 1791, dois séculos após as primeiras tentativas de instituição de uma educação com esse objetivo. A iniciativa foi concebida pelo religioso francês Michel de L'Epée (1712-1789), que desenvolveu um método gestualístico que pode ser entendido como a primeira prática de educação para surdos, considerando que os surdos já se utilizavam de uma linguagem mímica.

Os referenciais teóricos de Olizaroski (2013) destacam que na história da educação de surdos no Brasil, Dom Pedro II teve uma importante participação, ao contratar o professor francês Hernest Huet, também surdo. Huet foi o criador, em 1857, da primeira escola para surdos no Brasil, o Instituto Nacional de Educação de Surdos (INES), que inicialmente ensinava os alunos surdos pela Língua de Sinais Francesa (LSF). Posteriormente, o professor Huet criou a Língua Brasileira de Sinais (Libras), que possibilitou uma melhor comunicação entre os surdos e os não surdos.

Com o passar do tempo, as escolas destinadas à educação de pessoas portadoras de surdez existentes ao redor do mundo acompanharam as tendências mundiais segundo as abordagens oralistas que eram adotadas na educação de surdos. No entanto, a tendência nos dias atuais, na educação de pessoas portadoras de surdez é priorizar a educação bilíngue, onde o aluno tem o ensino organizado metodologicamente oferecendo a Libras e a língua portuguesa ao mesmo tempo.

Em relação à educação de surdos no estado de Minas Gerais, em 10 de janeiro de 1991, é criada a Lei Estadual No 10379 (MINAS GERAIS, 1991), que passa a reconhecer oficialmente como meio de comunicação objetiva e de uso corrente, a linguagem gestual codificada na Língua Brasileira de Sinais (Libras). O ano de 2006 tem como marco inicial o Dia Estadual do Surdo, instituído no estado pela Lei $\mathrm{N}^{\circ} 16500$, de 21 de dezembro de 2006.

O capitulo 3, O ensino da língua brasileira de sinais na modalidade a distância: Universidade do Estado de Minas Gerais - Poços de Caldas, apresentou o resultado das entrevistas com os 
gestores do Curso de Pedagogia da Unidade Poços de Caldas, onde se constatou alguns impactos pedagógicos na formação dos pedagogos formados nesse curso, que oferece a disciplina Libras na modalidade a distância.

Durante os estudos investigativos percebeu-se que é de fundamental importância o papel do tutor para trocas de informações, esclarecimentos e orientações sobre os referenciais teóricos e textuais,conforme aponta Miranda (2021, p.1950):

Mediar a aprendizagem no ambiente virtual de aprendizagem na dimensão atitudinal se reveste de uma ação motivacional em que o tutor a distância procura despertar no educando o desejo de aprender, de estudar, de cursar a disciplina, de continuar no curso.

A ausência de um intérprete de língua de sinais e do professor-tutor descaracteriza um atendimento didático pedagógico diferenciado, para um conteúdo e em uma modalidade de ensino também diferenciados, o que acaba por desmotivar o discente nas atividades pedagógicas.

Considera-se que é um desafio pedagógico a formação de pedagogos em cursos de graduação, do qual faz parte o ensino da Libras, diante do método do ensino oferecido no desenvolvimento das atividades no ambiente digital do curso, da precariedade no desenvolvimento das plataformas de implementação, como também pelo desrespeito às metodologias de ensino da língua de sinais, que não contemplam as estratégias didático metodológicas que esse tipo de conteúdo exige.

Evidencia-se que há a necessidade de uma contribuição maior para que a formação dos novos pedagogos seja consolidada de forma efetiva, pela oferta de materiais didáticos de qualidade, conteúdos que favoreçam uma melhor compreensão e assimilação das atividades didáticas interacionais, como também de políticas públicas de incentivo para o aperfeiçoamento dos cursos de educação a distância e aprimoramento de seu desenvolvimento e práticas.

É evidente que as TICs trouxeram alternativas para facilitar a democratização da educação através da inclusão digital. Pela sua organização e utilização de ferramentas de ensino inseridas no cotidiano educacional com colaboração das estratégias de ensino e conteúdos didáticos preparados, com o recurso do uso da tecnologia através do acesso a informações, troca de mensagens e experiências. Contudo, o ensino da Libras em EaD possui características de ensino e aprendizagem que necessita de um bom planejamento, conteúdo curricular que vá além do ensino dos sinais e seus gestuais, de metodologia diferenciada para o desenvolvimento de um aprendizado e saber mais efetivo. Dessa forma o aluno terá, pela plataforma virtual, acesso ao conhecimento com mais percepção e entendimento sobre o conteúdo.

Porém, na organização dessas tecnologias é necessário que o aluno tenha também o 
conhecimento de onde buscar e como encontrar informações confiáveis, com acesso a diferentes fontes de saber e cultura, com competência de navegação e comprometimento com o estudo e pesquisa. Desse modo, um curso de Libras em EaD não pode oferecer única e exclusivamente o conteúdo específico.

Nesse sentido, autores Santos et al. (2015), destacam que é preciso haver uma formação de qualidade também para os docentes; para que busquem e compreendam, de maneira a modificar sua prática e o ensino, as TICs como um grande avanço na inclusão social. Os autores destacam que na $\mathrm{EaD}$ observa-se uma falta de atenção com os alicerces dos conhecimentos pedagógicos e metodológicos; e é preciso que o ensino seja capaz de possibilitar a construção de conhecimentos por parte do aluno, fazendo com que ele utilize os recursos da tecnologia em uma interação dialógica.

É preciso pensar a modalidade de educação a distância como uma ferramenta metodológica que deve efetivar os objetivos da educação de qualidade para todos e não apenas como ferramenta tecnológica, na intenção de colocar as instituições educadoras no campo da modernidade pela posse das novas tecnologias da informação e comunicação.

Espera-se, a partir das discussões aqui apresentadas, contribuir para que se compreenda a importância de problematizar a modalidade da oferta do ensino de Libras na modalidade à distância nos cursos de formação docente. E que se repense essa oferta, visto que, a partir de nosso estudo, entendemos que para um aprendizado de qualidade é necessário que haja interação entre os envolvidos, considerando sua cultura e costumes próprios. 


\section{REFERÊNCIAS}

ALVES, Lucineia. Educação a distância: conceitos e história no Brasil e no mundo. Revista Brasileira de Aprendizagem Aberta e a Distância, São Paulo, v. 10, p. 83-92, 2011. Disponível em: <http://www.abed.org.br/revistacientifica/_Brazilian/edicoes/2011/2011_Edicaov10.ht m>. Acesso em: 20 ago. 2019.

AZEVEDO, Lorna das G. M. R. P. P. de; DA LUZ, Maria de Fátima; FONTES, Priscila R. R. C. T. Implantação de disciplinas na modalidade à distância em cursos de graduação presencial na universidade pública. Revista Científica ICGAP, São Bernardo do Campo, SP, v. 1, n. 1, 2018. Disponível em:

<http://www.revistaicgap.com.br/index.php/icgap/issue/view/1>. Acesso em: 20 ago. 2019.

BERNARDINO, Elidéa L. A.; PASSOS, Rosana. Ensino de Libras on-line. Anais do Congresso Internacional da Abralin, 8., p. 1278-1288, Curitiba, 2011. Disponível em:

$<$ https://www.researchgate.net/profile/Elidea_Bernardino/publication/275959978_Ens

ino_de_Libras_On-line/links/554ba5910cf29752ee7d7710/Ensino-de-Libras-On- line.pdf >. Acesso em: 27 mar. 2020.

BRASIL. Ministério da Educação. Decreto No 9.057, de 25 de maio de 2017. DECRETO No 9.057, DE 25 DE MAIO DE 2017. Regulamenta o Art. No 80 da Lei nº 9.394, de 20 de dezembro de 19967, que estabelece as diretrizes e bases da educação nacional. Diário Oficial da União seção 1 p. 9 ISSN 1677-7042.

http://portal.mec.gov.br/index.php?option=com_docman\&view=download\&alias=66 431-portarianormativa-11-pdf\&category_slug=maio-2017-pdf\&Itemid=30192>.Acesso em: 20 abr. 2019.

BRASIL. Ministério da Educação. Secretaria de Educação a Distância. Referenciais de qualidade para educação superior a distância. Brasília: MEC/SEED, 2007.Disponível em: <http://portal.mec.gov.br/seed/arquivos/pdf/legislacao/refead1.pdf>. Acesso em: 20 abr. 2019.

BRASIL. Ministério da Educação. Portaria No 4.059, de 10 de dezembro de 2004. Regulamenta a oferta de disciplinas integrantes do currículo que utilizem modalidade semi-presencial nas instituições de ensino superior. Brasília: MEC, 2004. Disponível em: <http://portal.mec.gov.br/sesu/arquivos/pdf/nova/acs_portaria4059.pdf>. Acesso em:

DE MIRANDA, Naíola Paiva. Avaliação dos saberes na mediação online na educação superior semipresencial: Knowledge evaluation in online mediation in semipresential higher education. Latin American Journal of Development, v. 3, n. 4, p. 1947-1954, 2021.

LANKSHEAR, Colin; KNOBEL, Michele. Pesquisa pedagógica: do projeto à implementação. Tradução Magda França Lopes. Porto Alegre: Artmed, 2008.

MINAS GERAIS. Assembleia Legislativa de Minas Gerais. Lei No 16500, de 21 de dezembro de 2006. Institui o dia estadual dos surdos. Minas Gerais: Diário do Executivo. 22 dez. 2006. p. 1, col 1. Disponível em:

<https://www.lexml.gov.br/urn/urn:lex:br;minas.gerais:estadual:lei:2006-12- 21;16500>. Acesso em: 20 abr. 2019.

MINAS GERAIS. Assembleia Legislativa de Minas Gerais. Lei No 14367, de 19 de julho de 2002. Dispõe sobre o atendimento a pessoa portadora de necessidades especiais em processo seletivo para 
ingresso em instituições de ensino superior. Minas Gerais: Diário do Executivo. 20 jul. 2002. p. 4, col 1. Disponível em:

<https://www.lexml.gov.br/urn/urn:lex:br;minas.gerais:estadual:lei:2002-07- 19;14367>. Acesso em: 20 abr. 2019.

MINAS GERAIS. Assembleia Legislativa de Minas Gerais. Lei No 10379, de 10 de janeiro de 1991. Reconhece oficialmente, no Estado de Minas Gerais, como meio de comunicação objetiva e de uso corrente, a linguagem gestual codificada na Língua Brasileira de Sinais - LIBRAS. Minas Gerais: Diário do Executivo. 11 jan. 1991. p. 4, col 2. Disponível em:

<https://www.lexml.gov.br/urn/urn:lex:br;minas.gerais:estadual:lei:1991-01- 10;10379>. Acesso em: 20 abr. 2019.

MIRANDA, João Paulo V. Voz passiva em Libras? Ou outras estratégias de topicalização? 2014. 91 f. Dissertação (Mestrado em Linguística) - Instituto de Letras, Universidade de Brasília, Brasília, 2014. Disponível em:

<https://www.repositorio.unb.br/bitstream/10482/16933/1/2014_JoaoPauloVitorioMira nda.pdf>. Acesso em: 20 ago. 2019.

MORI, Nerli N. R.; SANDER, Ricardo E. História da Educação dos Surdos no Brasil. Anais do Simpósio de Pesquisa do PPE- Universidade Estadual de Maringá 02 a 04 de dezembro de 2015. Disponível em www.ppe.uem.br/publicações-ppe- 2015/trabalhos/co-04/94.pdf .p.4 acesso em 02 jul.2020

MUTTÃO, Melaine D. R.; LODI, Ana Claudia B. Formação de professores e educação de surdos: revisão sistemática de teses e dissertações. Psicologia Escolar e Educacional, São Paulo, número especial, p. 49-56, 2018. Disponível em: <http://www.scielo.br/pdf/pee/v22nspe/2175-3539-pee-22spe-49.pdf>. Acesso em: 05 mar. 2020.

NUNES, Ivônio B. A história da EAD no mundo. In: LITTO, Fredric M.; FORMIGA, Manuel Marcos M. (orgs.). Educação a distância: o estado da arte. 8. ed. São Paulo: Pearson Education do Brasil, 2009. p. $2-8$.

OLIZAROSKI, Iara Mikal Holland. Trajetória histórica do sujeito surdo e reflexões sobre as políticas públicas que regem a educação do surdo no brasil. JORNADA DO HISTEDBR, 11., 2013, Campinas. Anais... Campinas: UNICAMP/HISTEDBR, 2013. ISSN: 2177-8892. Disponível em: <http://www.histedbr.fe.unicamp.br/acer_histedbr/jornada/jornada11/artigos/6/simpos io6.html>. Acesso em: 20 ago. 2019.

PEREIRA, Maria de Fátima R.; MORAES, Raquel de Almeida; TERUYA, Teresa Kazuko (Orgs.) Educação a distância (EaD): reflexões críticas e práticas.

Uberlândia: Navegando Publicações, 2017. Disponível em:

<https://www.ead.unb.br/arquivos/livros/ead_reflexoes_critica_praticas.pdf>. Acesso em: 20 ago. 2019.

RODRIGUES JUNIOR, Emílio; FERNANDES, Frabrício Juliano. Proposta de inclusão de carga horária semipresencial em cursos superiores presenciais. Avaliação (Campinas), Sorocaba, v. 19, n. 1, p. 179-192. Mar. 2014.

SANTOS, Lara Ferreira dos et al. Desafios tecnológicos para o ensino de Libras na educação a distância. Comunicações, Piracicaba, v. 22, n. 3, p. 203-219, 2015. 
Disponível em: https://www.metodista.br/revistas/revistasunimep/index.php/comunicacoes/article/vie wFile/2252/1647. Acesso em: 20 abr. 2020.

STROBEL, Karin. História da educação de surdos. Florianópolis, SC: UFSC/DALI, 2009. Disponível em:

<http://www.libras.ufsc.br/colecaoLetrasLibras/eixoFormacaoEspecifica/historiaDaEducacaoDeSurd os/assets/258/TextoBase_HistoriaEducacaoSurdos.pdf>. Acesso em: 20 ago. 2019.

TARCIA, Rita M. L.; CABRAL, Ana Lucia T. O novo papel do professor na ead. In: LITTO, Fredric M.; FORMIGA, Marcos (orgs.). Educação a distância: o estado da arte. v. 2. 2. ed. São Paulo: Pearson Education do Brasil, 2012. p. 148-153.

Disponível em: <http://www.abed.org.br/arquivos/Estado_da_Arte_2.pdf>. Acesso em: 27 fev. 2020.

VILELAS, José. Investigação: o processo de construção do conhecimento. Lisboa: Edições Sílabo Lda., 2009. 